\title{
A 9-Connected Zirconium-Based Metal-Organic Framework for
}

\author{
Ammonia Capture
}

Yongwei Chen, ${ }^{\mathrm{a}, \mathrm{b}}$ Xuan Zhang, ${ }^{\mathrm{b}}$ Kaikai Ma, ${ }^{\mathrm{b}}$ Zhijie Chen, ${ }^{\mathrm{b}}$ Xingjie Wang, ${ }^{\mathrm{a}, \mathrm{b}}$ Julia Knapp, ${ }^{\mathrm{b}}$ Selim Alayoglu, ${ }^{\mathrm{c}}$ Fenfen Wang, ${ }^{\mathrm{b}}$ Qibin Xia, ${ }^{\mathrm{a}}$ Zhong Li, ${ }^{\mathrm{a}}$ Timur Islamoglu, ${ }^{\mathrm{b}}$ and Omar K. Farha*,b, d

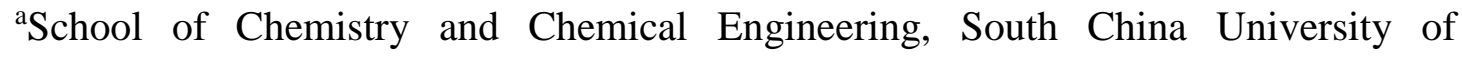
Technology, Guangzhou 510640, P. R. China

${ }^{b}$ Department of Chemistry and International Institute of Nanotechnology, Northwestern University, 2145 Sheridan Road, Evanston, Illinois 60208, United States

${ }^{\mathrm{c} R e a c t o r}$ Engineering and Catalyst Testing Core, Northwestern University, 2145 Sheridan Road, Evanston, Illinois 60208, United States

${ }^{\mathrm{d} D e p a r t m e n t}$ of Chemical and Biological Engineering, Northwestern University, 2145 Sheridan Road, Evanston, Illinois 60208, United States

\begin{abstract}
Construction of multifunctional metal-organic frameworks (MOFs) with asymmetric connectivity have the potential to expand the scope of their utilization. Herein, we report a robust 9-connected microporous Zr-based MOF, NU-300, assembled from asymmetric tri-carboxylate ligands and $\mathrm{Zr}_{6}$ nodes. As indicated by single-crystal $\mathrm{X}$-ray diffraction analysis, there exist uncoordinated carboxylate groups in the structure of NU-300 that can participate in ammonia $\left(\mathrm{NH}_{3}\right)$ sorption through acid-base interactions which yield high uptake of $\mathrm{NH}_{3}$ at low pressure regions ( $<0.01$ bar). In situ infrared (IR) spectroscopy shows the interactions between Brønsted acidic sites and $\mathrm{NH}_{3}$, which
\end{abstract}


suggests that $\mathbf{N U - 3 0 0}$ can be used as a sorbent for $\mathrm{NH}_{3}$ capture at low pressures.

\section{Introduction}

Metal-organic frameworks (MOFs) are a class of porous crystalline materials assembled by metal nodes and organic ligands. ${ }^{1,2}$ Because of their high porosity, ${ }^{3}$ versatile pore structures, ${ }^{4}$ and tunable chemical functionalities, ${ }^{5-7}$ MOFs can be precisely designed at the molecular level for targeted applications including, but not limited to, gas storage ${ }^{8-10}$ and separation, ${ }^{11-16}$ catalysis $^{17-19}$, chemical sensing, ${ }^{20,21}$ and more. $^{22,23}$ Particularly, zirconium-based MOFs (Zr-MOFs) have attracted extensive attention in recent years due to their high thermal and chemical robustness, as well as topological diversity. ${ }^{24,} 25$ Many reported Zr-MOFs contain 12-, 10-, 8-, 6- or 4connected $\mathrm{Zr}_{6}$ nodes with di-, tri-, and tetra-carboxylate ligands, showcasing different network topologies. ${ }^{26}$ In designing stable zirconium MOFs, in general, highly symmetric di-, tri-, and tetra-carboxylate ligands are used which results in high symmetry MOFs when combined with symmetric $\mathrm{Zr}_{6}$ nodes. ${ }^{24,}{ }^{25}$ In the case of asymmetric ligands, although copper and rare-earth (RE) based MOFs have been constructed with non-planar tri-carboxylate ligands, ${ }^{27,}{ }^{28}$ however, Zr-based MOFs have rarely been explored. ${ }^{29}$ Asymmetric ligands can introduce new types of coordination environments and potentially unlock new topological structures for novel MOF materials. ${ }^{27}$ Thus, the construction of Zr-MOFs with asymmetric ligands remains under explored for understanding the relationship between the different connected $\mathrm{Zr}_{6}$ nodes and ligands within their unique structures, as well as exploiting the potential chemical properties related to the asymmetric ligands. 
The exceptional stability of Zr-MOFs renders them as promising candidates for the capture of ammonia $\left(\mathrm{NH}_{3}\right) \cdot{ }^{30-32}$ Considering the associated corrosiveness and toxicity, the capture of $\mathrm{NH}_{3}$ at extremely low concentrations using porous materials under ambient conditions in industrial settings is of great importance to comply with limits of short-term exposure (35 ppm) and long-term exposure ( $25 \mathrm{ppm})$ set by the Occupational Safety and Health Administration (OSHA) ${ }^{31}$ Several MOFs including HKUST-1, ${ }^{33}$ MOF-74, ${ }^{34} \mathrm{M}(\text { isonicotinic acid })_{2}(\mathrm{M}=\mathrm{Zn}, \mathrm{Co}, \mathrm{Cu}, \mathrm{Cd}),{ }^{35} \mathrm{MFM}-300(\mathrm{Al}),{ }^{36}$ $\mathrm{M}_{2} \mathrm{Cl}_{2} \mathrm{BBTA}(\mathrm{M}=\mathrm{Co}, \mathrm{Mn}),{ }^{37} \mathrm{M}_{2} \mathrm{Cl}_{2}$ (BTDD) $(\mathrm{M}=\mathrm{Mn}, \mathrm{Co}, \mathrm{Ni}$ and $\mathrm{Cu}),{ }^{38}$ and UiO-66 series ${ }^{30,32}$ have been tested for $\mathrm{NH}_{3}$ uptake. However, the majority of MOFs studied for $\mathrm{NH}_{3}$ uptake showed structural degradation upon exposure or significant loss of uptake after consecutive cycles. So far, only a limited number of MOFs are reported to exhibit good reversible $\mathrm{NH}_{3}$ sorption over multiple cycles, e.g. MFM-300(Al), $\mathrm{Co}_{2} \mathrm{Cl}_{2} \mathrm{BBTA}$ and $\mathrm{M}_{2} \mathrm{Cl}_{2}$ (BTDD). ${ }^{36-38}$ The development of robust MOFs with reversible $\mathrm{NH}_{3}$ sorption that can withstand multiple cycles remains challenging.

With the aforementioned challenges in mind, herein, we report a robust and functional 9-connected microporous Zr-MOF (NU-300) assembled from an asymmetric tri-carboxylate ligand and novel $\mathrm{Zr}_{6}$ node with an unusual linker connectivity. Notably, NU-300 has a high ammonia uptake at low pressures by exploiting Brønsted acidic sites on both the ligand and the node, which can be used an adsorbent for $\mathrm{NH}_{3}$ capture at low concentration.

\section{Result and Discussion}

The solvothermal reactions of $\mathrm{ZrCl}_{4}$ and 3,5-di(4'-carboxylphenyl)benzoic acid 
$\left(\mathrm{H}_{3} \mathrm{~L}\right)$ in N,N-dimethylformamide (DMF) with formic acid as a modulator, yielded colorless rhombic-shaped crystals of NU-300 (NU stands for Northwestern University). Single crystal X-ray diffraction revealed that NU-300 crystallizes in the orthorhombic Imma space group. The asymmetric unit of NU-300 contains four $\mathrm{Zr}^{4+}$ atoms, each uniquely eight-coordinated. As shown in Figure 1a, Zr1 is coordinated by four distinct oxygen atoms from different carboxylates of four $\mathrm{H}_{3} \mathrm{~L}$ ligands and four $\mu_{3}-\mathrm{O}$ entities. $\mathrm{Zr} 2$ is coordinated by two distinct oxygen atoms from carboxylates of two $\mathrm{H}_{3} \mathrm{~L}$ ligands, one oxygen atom from formic acid, one oxygen atoms from DMF and four $\mu_{3}-\mathrm{O}$ entities. $\mathrm{Zr} 3$ is coordinated by three oxygen atoms from various carboxylates of three $\mathrm{H}_{3} \mathrm{~L}$ ligands, one oxygen from DMF and four $\mu_{3}-\mathrm{O}$ entities. Finally, $\mathrm{Zr} 4$ is coordinated by three oxygen atoms from various carboxylates of three $\mathrm{H}_{3} \mathrm{~L}$ ligands, one oxygen from terminal $\mathrm{OH} / \mathrm{H}_{2} \mathrm{O}$ and four $\mu_{3}-\mathrm{O}$ entities. Two $\mathrm{Zr} 1$, two $\mathrm{Zr}$ 2, one $\mathrm{Zr} 3$ and one $\mathrm{Zr} 4$ atoms are connected together by eight $\mu_{3}-\mathrm{O}$ atoms to form the $\mathrm{Zr}_{6} \mathrm{O}_{8}$ cluster (Figure S2). This cluster differs from previously reported $\mathrm{Zr}_{6}$ nodes that contain only one or two crystallographically independent $\mathrm{Zr}^{4+}$ atoms. ${ }^{26,29,39-42}$

Moreover, the $\mathrm{H}_{3} \mathrm{~L}$ ligand adopts two types of coordination modes. In mode I, two carboxylate groups of $\mathrm{H}_{3} \mathrm{~L}$ adopt a bridging bis-monodentate mode while one is monodentate (Figure 1b). In mode II, two carboxylate groups of $\mathrm{H}_{3} \mathrm{~L}$ adopt monodentate and bridging bis-monodentate modes, respectively, while one carboxylate group remains uncoordinated (Figure 1c) and points to the channel along the $a$-axis in the 3D structure of NU-300 (Figure 1d). The topological analysis indicates that NU300 consists of 9-connected $\mathrm{Zr}_{6}$ nodes and three crystallographically independent 
tritopic linkers, since monodentate carboxylic acids are not included in the connectivity counting. Thus, the 3D framework of NU-300 can be simplified as a $(3,3,3,9)$ connected network with a point symbol of $\left(4.6^{2}\right)\left(4^{2} .6\right)_{2}\left(4^{8} .6^{20} .8^{8}\right)$ (Figure 1e), which is a new topology. The 9-connected $\mathrm{Zr}_{6}$ nodes of $\mathbf{N U - 3 0 0}$ are different from a previously reported 9-connect node, wherein the carboxylate ligands bridge adjacent $\mathrm{Zr}$ atoms in the node. ${ }^{29}$

(a)

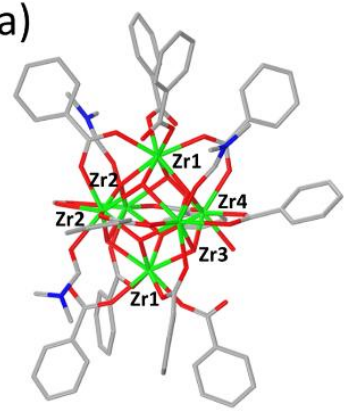

(b)

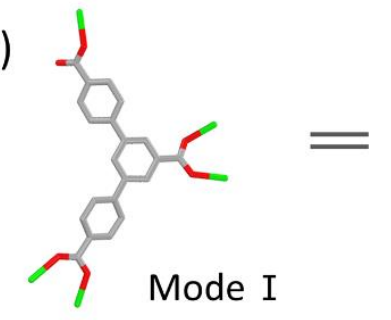

(c)

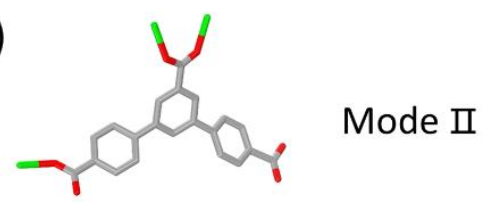

(d)
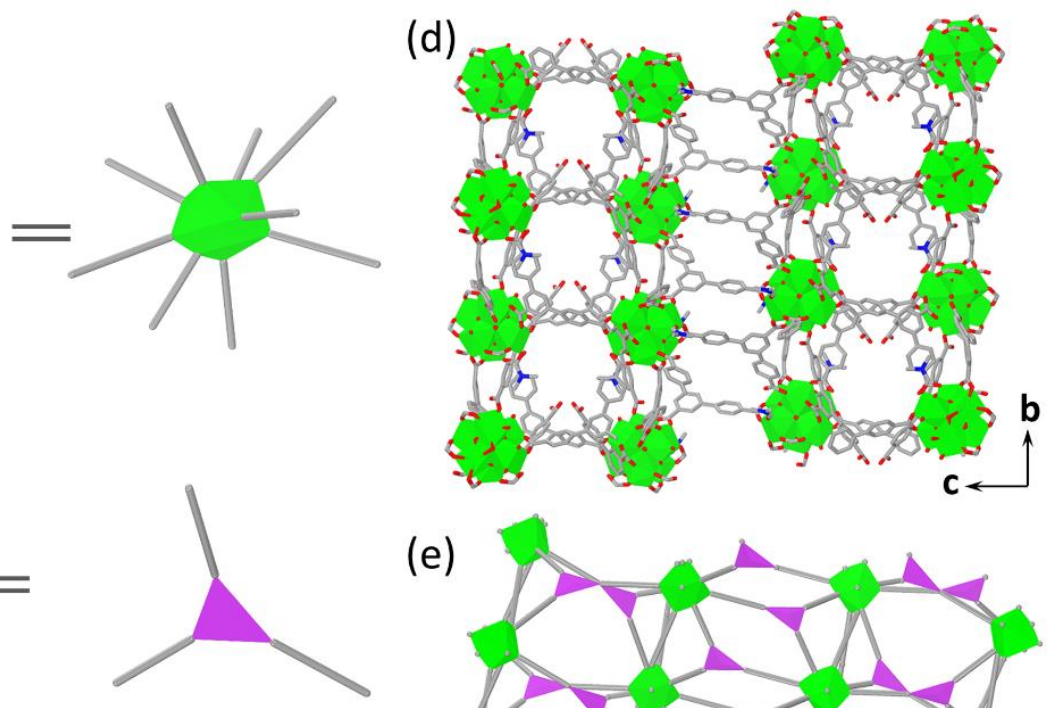

(e)

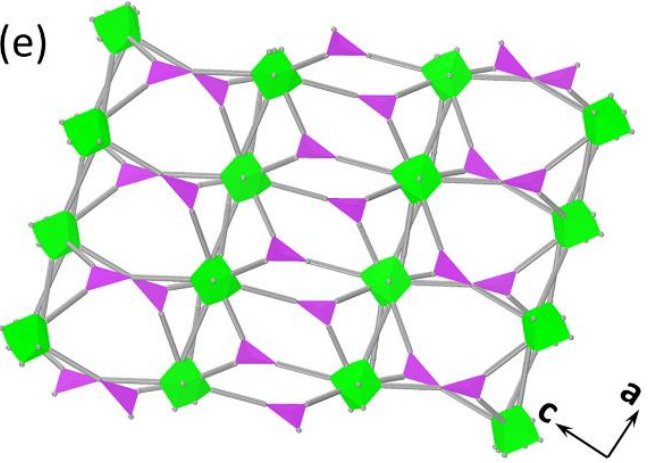

Figure 1. Single-crystal structure for NU-300: (a) Coordination environment of the node and schematic representation of each 9-connected $\mathrm{Zr}^{4+}$. (b) Coordination mode I of the $\mathrm{H}_{3} \mathrm{~L}$ ligand and schematic representation of the 3-connected ligand. (c) Coordination mode II of the $\mathrm{H}_{3} \mathrm{~L}$ ligand. (d) The 3D structure of NU-300 viewed along the $a$ direction. (e) Schematic representation of the $(3,3,3,9)$-connected networks of NU-300 (Zr, green; C, grey; O, red). 
The phase purity of bulk NU-300 is confirmed by comparison of simulated and experimental PXRD patterns (Figure 2a). Thermogravimetric analysis (TGA) reveals that the framework of NU-300 starts to decompose at around $400{ }^{\circ} \mathrm{C}$ in air (Figure S3), demonstrating the high thermal stability of NU-300. The permanent porosity of NU300 is confirmed by $\mathrm{N}_{2}$ adsorption measurements at $77 \mathrm{~K}$ (Figure $2 b$ ). NU-300 exhibits a type I isotherm, indicative of the microporous character of the material. The BrunauerEmmett-Teller (BET) area and total pore volume for NU-300 are calculated to be 1470 $\mathrm{m}^{2} / \mathrm{g}$ and $0.58 \mathrm{~cm}^{3} / \mathrm{g}$, respectively, while the pore size distribution based on DFT modeling indicates micropores of $\sim 11 \AA$ (Figure $2 b$ ). 

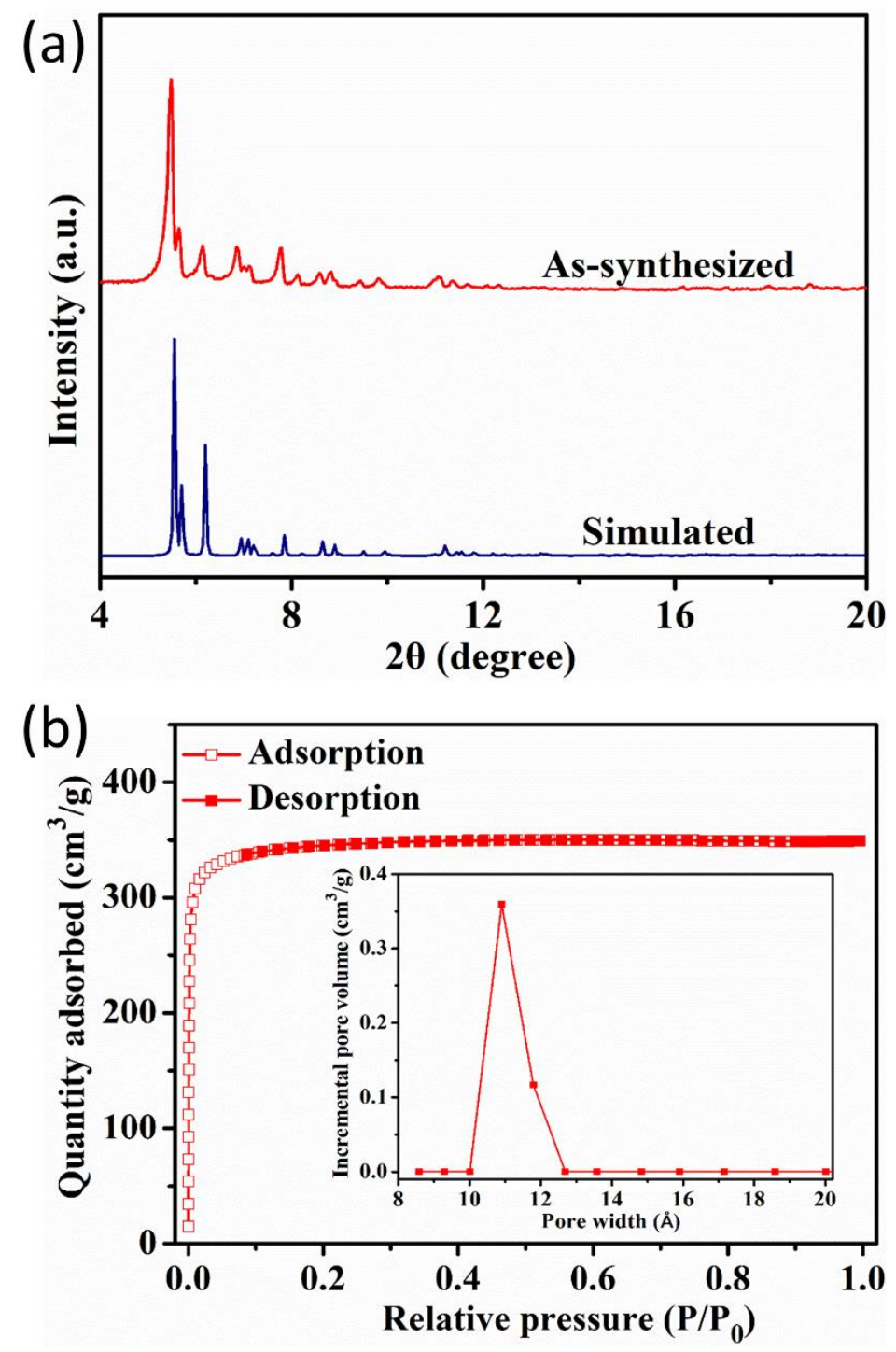

Figure 2. (a) PXRD patterns of the simulated and as-synthesized NU-300. (b) $\mathrm{N}_{2}$ sorption isotherms at $77 \mathrm{~K}$ and DFT pore size distribution of NU-300.

The chemical stability of NU-300 is then investigated by soaking $\mathbf{N U - 3 0 0}$ in $100^{\circ} \mathrm{C}$ $\mathrm{H}_{2} \mathrm{O}, 0.01 \mathrm{M}$ aqueous $\mathrm{HCl}(\mathrm{pH}=2)$ and $0.001 \mathrm{M}$ aqueous $\mathrm{NaOH}(\mathrm{pH}=11)$ solutions for 24 h. As illustrated by PXRD patterns (Figure 3a), the crystallinity of the NU-300 is retained after these treatments. To further confirm the chemical stability of NU-300, $\mathrm{N}_{2}$ sorption measurements are also conducted after these treatments (Figure $3 \mathrm{~b}$ ). The $\mathrm{N}_{2}$ isotherms of NU-300 in hot water and acidic conditions are almost identical to that of 
pristine NU-300, confirming its structural integrity and permanent porosity after exposure to boiling water and dilute acid. However, a decrease is observed in surface area and pore volume after base treatment.
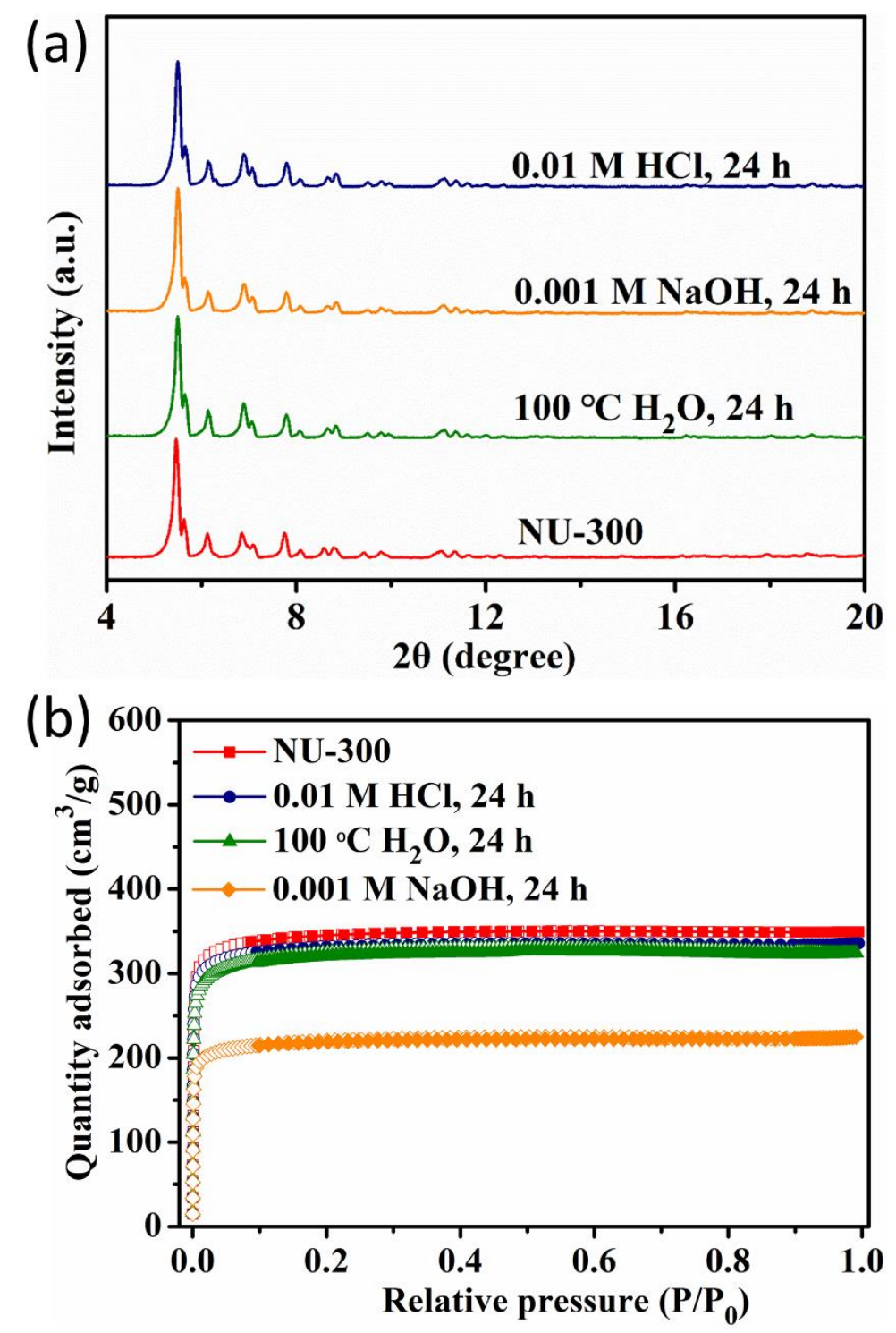

Figure 3. (a) PXRD patterns and (b) $\mathrm{N}_{2}$ sorption isotherms at $77 \mathrm{~K}$ of $\mathbf{N U - 3 0 0}$ after treatment with $100{ }^{\circ} \mathrm{C} \mathrm{H}_{2} \mathrm{O}, 0.01 \mathrm{M} \mathrm{HCl}$ and $0.001 \mathrm{M} \mathrm{NaOH}$ for $24 \mathrm{~h}$ (open symbols, adsorption; solid symbols, desorption).

In light of the presence of free carboxylate groups (-COOH) within the framework, $\mathrm{NH}_{3}$ sorption tests were conducted on $\mathbf{N U - 3 0 0}$ to investigate potential guest-host 
interaction. The first run adsorption-desorption isotherm shows an adsorbed $\mathrm{NH}_{3}$ amount of $8.28 \mathrm{mmol} / \mathrm{g}$ at $298 \mathrm{~K}$ and $1.0 \mathrm{bar}$ (Figure 4a). At pressures less than 0.01 bar (Figure 4b), $\mathrm{NH}_{3}$ molecules preferentially adsorbed to the $\mathrm{Zr}_{6}$ nodes and Brønsted acidic sites of the free $-\mathrm{COOH}$ groups in $\mathbf{N U - 3 0 0}$, exhibiting the steep $\mathrm{NH}_{3}$ isotherm. After regeneration at room temperature under vacuum, an $\mathrm{NH}_{3}$ uptake of $3.30 \mathrm{mmol} / \mathrm{g}$ remained in NU-300, likely due to the chemisorption process by the formation of strong interactions between the uncoordinated - $\mathrm{COOH}$ groups and $\mathrm{NH}_{3}$ molecules, apart from the acidic -OH groups on $\mathrm{Zr}_{6}$ nodes (Figure S5). This indicates that Brønsted acid sites, particularly the free $-\mathrm{COOH}$ groups, aid $\mathbf{N U - 3 0 0}$ in $\mathrm{NH}_{3}$ uptake at low pressures, allowing NU-300 to reach approximately $4 \mathrm{mmol} / \mathrm{g}$ uptake by 0.10 bar and $1.5 \mathrm{mmol} / \mathrm{g}$ by 0.01 bar, and the latter can be recycled for at least three times (Figure $4 \mathrm{~b}$ ). There was a loss in $\mathrm{NH}_{3}$ uptake capacity at 1 bar between the first and second cycles while the third cycle of $\mathrm{NH}_{3}$ sorption was nearly identical (5.71 and $5.41 \mathrm{mmol} / \mathrm{g}$ at $1.0 \mathrm{bar}$ ), suggesting that the loss in capacity occurs primarily in the initial sorption cycle. 

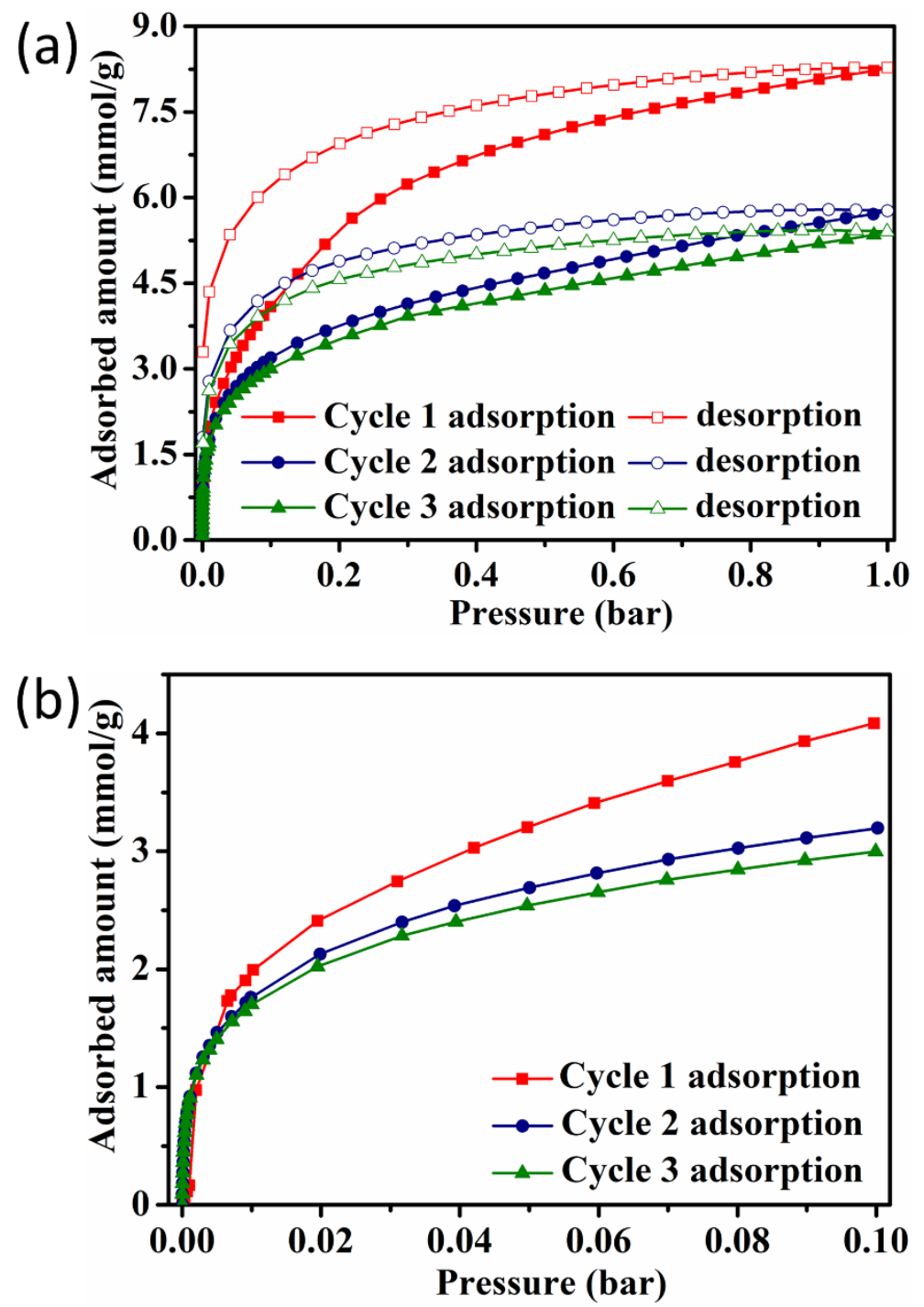

Figure 4. (a) Three cycle $\mathrm{NH}_{3}$ sorption isotherms of NU-300 at $298 \mathrm{~K}$ and (b) low pressure range of 0-0.1 bar for clarity.

We then turned to IR spectroscopy to further assess how the carboxylic acid sites in NU-300 interact with $\mathrm{NH}_{3}$ molecules during the adsorption and desorption processes. As observed in Figure 5, with $\mathrm{NH}_{3}$ exposure for $60 \mathrm{~min}$ on $\mathbf{N U - 3 0 0}$, two characteristic $\mathrm{NH}_{3}$ bands are observed, indicating $\mathrm{NH}_{3}$ interactions with $\mathbf{N U - 3 0 0}$ : the degenerate and symmetric deformation of $\mathrm{NH}_{3}$ at 1625 and $1360 \mathrm{~cm}^{-1}$, respectively. ${ }^{43}$ The location of $\mathrm{C}=\mathrm{O}$ stretching vibration of the free $-\mathrm{COOH}$ groups at $1730 \mathrm{~cm}^{-1}$ (Figure $\mathrm{S} 7$ ) decreases 
to $1710 \mathrm{~cm}^{-1}$ upon $\mathrm{NH}_{3}$ exposure, possibly due to deprotonation and subsequent resonance that weaken the $\mathrm{C}=\mathrm{O}$ bond strength. ${ }^{44}$ The appearance of overlapping bands between 3300 and $3700 \mathrm{~cm}^{-1}$ supports the deprotonation of -COOH by NH $3 .{ }^{45}$ However, none of these bands between 3300 and $3700 \mathrm{~cm}^{-1}$ disappear upon $\mathrm{Ar}$ purge. $\mathrm{NH}_{3}$ exposure also results in a new band at $1480 \mathrm{~cm}^{-1}$, which could be assigned to the vibration of $\mathrm{N}-\mathrm{H}$ in $\mathrm{NH}_{4}{ }^{+} \cdot{ }^{43}$ These observations indicate that $\mathrm{NH}_{3}$ molecules were protonated in acid-base reaction with Brønsted acidic sites. IR spectra showed that even after Ar purge residual adsorbed ammonia bands were still present which rationalized the loss in uptake between the first and second cycles.

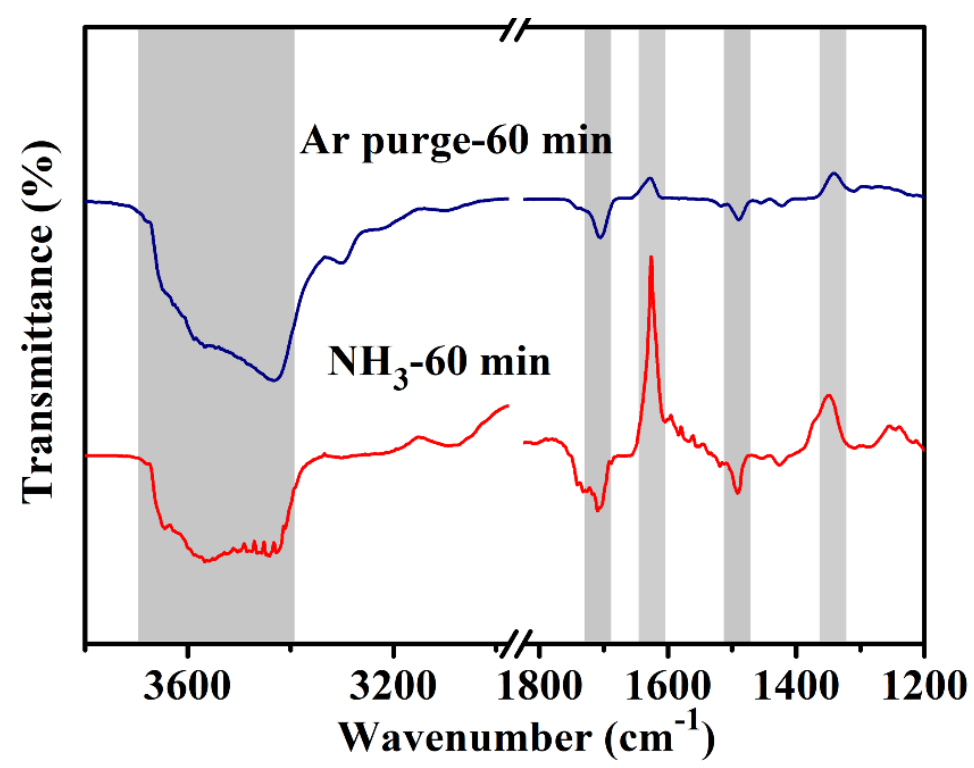

Figure 5. IR spectra of in situ $\mathrm{NH}_{3}$ adsorption and desorption on NU-300 at $373 \mathrm{~K}$ with relevant bands highlighted in gray.

\section{Conclusions}

In summary, we have designed a robust 9-connected Zr-based MOF, NU-300 using an asymmetric tri-carboxylate ligand. The presence of free - $\mathrm{COOH}$ groups on the ligands provides NU-300 with relevant functional properties for the chemisorption of $\mathrm{NH}_{3}$ 
molecules at low partial pressures. For the first cycle adsorption, the adsorbed uptake of $\mathrm{NH}_{3}$ was $8.28 \mathrm{mmol} / \mathrm{g}$ at $298 \mathrm{~K}$ and $1.0 \mathrm{bar}$. On the other hand, the second and third cycles of $\mathrm{NH}_{3}$ sorption showed reduced $\mathrm{NH}_{3}$ capacity compared to the first cycle, indicating saturation of the chemisorption of $\mathrm{NH}_{3}$ in the first cycle. By in situ IR measurement of $\mathrm{NH}_{3}$ adsorption and desorption, we observed that the ammonium band in the spectra which suggested the interactions between Brønsted acidic sites and $\mathrm{NH}_{3}$ molecules. The chemical interaction of $\mathrm{NH}_{3}$ and the framework indicated efficiency of introducing uncoordinated Brønsted acidic sites for achieving high $\mathrm{NH}_{3}$ uptakes at low concentrations for air filtration applications.

\section{ASSOCIATED CONTENT}

\section{Supporting Information}

Crystallographic data for NU-300 (CIF)

Materials synthesis and characterization, optical images of NU-300 single crystals, crystallographic data for $\mathbf{N U - 3 0 0}, \mathrm{Zr}_{6}$ node in NU-300, TGA curves, SEM images, DRIFTS spectrum, proton NMR spectra, IR spectra of in situ $\mathrm{NH}_{3}$ adsorption and desorption on NU-300 at $373 \mathrm{~K}$

\section{AUTHOR INFORMATION}

\section{Corresponding Author}

*E-mail: o-farha@,northwestern.edu

\section{Notes}

The authors declare no competing financial interest.

\section{ACKNOWLEDGMENT}


O. K. F. gratefully acknowledges support from the Defense Threat Reduction Agency (HDTRA1-19-1-0007). This work made use of the EPIC facility of Northwestern University's NUANCE Center, which has received support from the Soft and Hybrid Nanotechnology Experimental (SHyNE) Resource (NSF NNCI-1542205); the MRSEC program (NSF DMR-1720139) at the Materials Research Center; the International Institute for Nanotechnology (IIN); the Keck Foundation; and the State of Illinois, through the IIN. This work made use of the IMSERC at Northwestern University, which has received support from the NSF (CHE-1048773 and DMR-0521267); Soft and Hybrid Nanotechnology Experimental (SHyNE) Resource (NSF NNCI-1542205); the State of Illinois and International Institute for Nanotechnology (IIN). Y.C. gratefully acknowledges support from China Scholarship Council (CSC) during his visit to Northwestern University (201806150078). Q.X. gratefully acknowledges support from the National Natural Science Foundation of China (No. 21878101) for the synthesis of the linker.

\section{REFERENCES}

(1) Zhou, H. C.; Long, J. R.; Yaghi, O. M., Introduction to metal-organic frameworks. Chem. Rev. 2012, 112, 673-4.

(2) Kitagawa, S.; Kitaura, R.; Noro, S.-i., Functional porous coordination polymers. Angew. Chem. Int. Ed. 2004, 43, 2334-2375.

(3) Farha, O. K.; Eryazici, I.; Jeong, N. C.; Hauser, B. G.; Wilmer, C. E.; Sarjeant, A. A.; Snurr, R. Q.; Nguyen, S. T.; Yazaydin, A. O.; Hupp, J. T., Metal-organic framework materials with ultrahigh surface areas: is the sky the limit? J. Am. Chem. Soc. 2012, 134, 15016-15021. 
(4) Liang, W.; Bhatt, P. M.; Shkurenko, A.; Adil, K.; Mouchaham, G.; Aggarwal, H.; Mallick, A.; Jamal, A.; Belmabkhout, Y.; Eddaoudi, M., A tailor-made interpenetrated MOF with exceptional carbon-capture performance from flue gas. Chem 2019, 5, 950-963.

(5) Islamoglu, T.; Goswami, S.; Li, Z.; Howarth, A. J.; Farha, O. K.; Hupp, J. T., Postsynthetic tuning of metal-organic frameworks for targeted applications. Acc. Chem. Res. 2017, 50, 805-813.

(6) Zhang, X.; Vermeulen, N. A.; Huang, Z.; Cui, Y.; Liu, J.; Krzyaniak, M. D.; Li, Z.; Noh, H.; Wasielewski, M. R.; Delferro, M.; Farha, O. K., Effect of redox "non-innocent" linker on the catalytic activity of copper-catecholate-decorated metal-organic frameworks. ACS Appl. Mater. Interfaces 2018, 10, 635-641.

(7) Wang, Z;; Cohen, S. M., Postsynthetic modification of metal-organic frameworks. Chem. Soc. Rev. 2009, 38, 1315-1329.

(8) Kundu, T.; Wahiduzzaman, M.; Shah, B. B.; Maurin, G.; Zhao, D., Solvent-induced control over breathing behavior in flexible metal-organic frameworks for natural-gas delivery. Angew. Chem. Int. Ed. 2019, 58, 8073-807.

(9) Kapelewski, M. T.; Runčevski, T.; Tarver, J. D.; Jiang, H. Z. H.; Hurst, K. E.; Parilla, P. A.; Ayala, A.; Gennett, T.; FitzGerald, S. A.; Brown, C. M.; Long, J. R., Record high hydrogen storage capacity in the metal-organic framework $\mathrm{Ni}_{2}(\mathrm{~m}-\mathrm{dobdc})$ at near-ambient temperatures. Chem. Mater. 2018, $30,8179-8189$.

(10) Wen, H.-M.; Li, B.; Li, L.; Lin, R.-B.; Zhou, W.; Qian, G.; Chen, B., A metal-organic framework with optimized porosity and functional sites for high gravimetric and volumetric methane storage working capacities. 2018, 30, 1704792.

(11) Wang, H.; Li, J., Microporous metal-organic frameworks for adsorptive separation of C5-C6 
alkane isomers. Acc. Chem. Res. 2019, 52, 1968-1978.

(12) Qazvini, O. T.; Babarao, R.; Shi, Z. L.; Zhang, Y. B.; Telfer, S. G., A robust ethane-trapping metal-organic framework with a high capacity for ethylene purification. J. Am. Chem. Soc. 2019, $141,5014-5020$.

(13) Chen, Y.; Qiao, Z.; Huang, J.; Wu, H.; Xiao, J.; Xia, Q.; Xi, H.; Hu, J.; Zhou, J.; Li, Z., Unusual moisture-enhanced $\mathrm{CO}_{2}$ capture within microporous PCN-250 frameworks. ACS Appl. Mater. Interfaces 2018, 10, 38638-38647.

(14) Li, J.; Jiang, L.; Chen, S.; Kirchon, A.; Li, B.; Li, Y.; Zhou, H. C., Metal-organic framework containing planar metal-binding sites: efficiently and cost-Effectively enhancing the kinetic separation of $\mathrm{C}_{2} \mathrm{H}_{2} / \mathrm{C}_{2} \mathrm{H}_{4}$. J. Am. Chem. Soc. 2019, 141, 3807-3811.

(15) Sen, S.; Hosono, N.; Zheng, J. J.; Kusaka, S.; Matsuda, R.; Sakaki, S.; Kitagawa, S., Cooperative bond scission in a soft porous crystal enables discriminatory gate opening for ethylene over ethane. J. Am. Chem. Soc. 2017, 139, 18313-18321.

(16) Wang, S. Q.; Mukherjee, S.; Patyk-Kazmierczak, E.; Darwish, S.; Bajpai, A.; Yang, Q. Y.; Zaworotko, M. J., Highly selective, high-capacity separation of o-xylene from C8 aromatics by a switching adsorbent layered material. Angew. Chem. Int. Ed. 2019, 58, 6630-6634.

(17) Ding, M.; Flaig, R. W.; Jiang, H. L.; Yaghi, O. M., Carbon capture and conversion using metalorganic frameworks and MOF-based materials. Chem. Soc. Rev. 2019, 48, 2783-2828.

(18) Zhang, X.; Huang, Z.; Ferrandon, M.; Yang, D.; Robison, L.; Li, P.; Wang, T. C.; Delferro, M.; Farha, O. K., Catalytic chemoselective functionalization of methane in a metal-organic framework. Nat. Catal. 2018, 1, 356-362.

(19) Grigoropoulos, A.; McKay, A. I.; Katsoulidis, A. P.; Davies, R. P.; Haynes, A.; Brammer, L.; 
Xiao, J.; Weller, A. S.; Rosseinsky, M. J., Encapsulation of crabtree's catalyst in sulfonated MIL101(Cr): enhancement of stability and selectivity between competing reaction pathways by the MOF chemical microenvironment. Angew. Chem. Int. Ed. 2018, 57, 4532-4537.

(20) Mallick, A.; El-Zohry, A. M.; Shekhah, O.; Yin, J.; Jia, J.; Aggarwal, H.; Emwas, A. H.; Mohammed, O. F.; Eddaoudi, M., Unprecedented ultralow detection limit of amines using a thiadiazole-functionalized $\mathrm{Zr}(\mathrm{IV})$-based metal-organic framework. J. Am. Chem. Soc. 2019, 141, 7245-7249.

(21) Zhang, X.; Saber, M. R.; Prosvirin, A. P.; Reibenspies, J. H.; Sun, L.; Ballesteros-Rivas, M.; Zhao, H.; Dunbar, K. R., Magnetic ordering in TCNQ-based metal-organic frameworks with hostguest interactions. Inorg. Chem. Front. 2015, 2, 904-911.

(22) Zhu, L.; Sheng, D.; Xu, C.; Dai, X.; Silver, M. A.; Li, J.; Li, P.; Wang, Y.; Wang, Y.; Chen, L.; Xiao, C.; Chen, J.; Zhou, R.; Zhang, C.; Farha, O. K.; Chai, Z.; Albrecht-Schmitt, T. E.; Wang, S., Identifying the recognition site for selective trapping of ${ }^{99} \mathrm{TcO}_{4}^{-}$in a hydrolytically stable and radiation resistant cationic metal-organic framework. J. Am. Chem. Soc. 2017, 139, 14873-14876.

(23) Lin, C. G.; Zhou, W.; Xiong, X. T.; Xuan, W.; Kitson, P. J.; Long, D. L.; Chen, W.; Song, Y. F.; Cronin, L., Digital control of multistep hydrothermal synthesis by using 3D printed reactionware for the synthesis of metal-organic frameworks. Angew. Chem. Int. Ed. 2018, 57, 16716-16720.

(24) Yuan, S.; Qin, J. S.; Lollar, C. T.; Zhou, H. C., Stable metal-organic frameworks with group 4 metals: current status and trends. ACS Cent. Sci. 2018, 4, 440-450.

(25) Chen, Z.; Hanna, S. L.; Redfern, L. R.; Alezi, D.; Islamoglu, T.; Farha, O. K., Reticular chemistry in the rational synthesis of functional zirconium cluster-based MOFs. Coord. Chem. Revi. 2019, 386, 32-49. 
(26) Zhang, Y.; Zhang, X.; Lyu, J.; Otake, K. I.; Wang, X.; Redfern, L. R.; Malliakas, C. D.; Li, Z.; Islamoglu, T.; Wang, B.; Farha, O. K., A flexible metal-organic framework with 4-connected $\mathrm{Zr}_{6}$ nodes. J. Am. Chem. Soc. 2018, 140, 11179-11183.

(27) Schnobrich, J. K.; Lebel, O.; Cychosz, K. A.; Dailly, A.; Wong-Foy, A. G.; Matzger, A. J., Linker-directed vertex desymmetrization for the production of coordination polymers with high porosity. J. Am. Chem. Soc. 2010, 132, 13941-13948.

(28) Wang, Y.; Feng, L.; Fan, W.; Wang, K. Y.; Wang, X.; Wang, X.; Zhang, K.; Zhang, X.; Dai, F.; Sun, D.; Zhou, H. C., Topology exploration in highly connected rare-earth metal-organic frameworks via continuous hindrance control. J. Am. Chem. Soc. 2019, 141, 6967-6975.

(29) He, T.; Zhang, Y. Z.; Kong, X. J.; Yu, J.; Lv, X. L.; Wu, Y.; Guo, Z. J.; Li, J. R., Zr(IV)-based metal-organic framework with T-shaped ligand: unique structure, high stability, selective detection, and rapid sdsorption of $\mathrm{Cr}_{2} \mathrm{O}_{7}^{2-}$ in Water. ACS Appl. Mater. Interfaces 2018, 10, 16650-16659.

(30) Mounfield, W. P.; Taborga Claure, M.; Agrawal, P. K.; Jones, C. W.; Walton, K. S., Synergistic effect of mixed oxide on the adsorption of ammonia with metal-organic frameworks. Ind. Eng. Chem. Res. 2016, 55, 6492-6500.

(31) DeCoste, J. B.; Peterson, G. W., Metal-organic frameworks for air purification of toxic chemicals. Chem. Rev. 2014, 114, 5695-5727.

(32) Chen, Z.; Wang, X.; Noh, H.; Ayoub, G.; Peterson, G. W.; Buru, C. T.; Islamoglu, T.; Farha, O. K., Scalable, room temperature, and water-based synthesis of functionalized zirconium-based metal-organic frameworks for toxic chemical removal. CrystEngComm 2019, 21, 2409-2415.

(33) Katz, M. J.; Howarth, A. J.; Moghadam, P. Z.; DeCoste, J. B.; Snurr, R. Q.; Hupp, J. T.; Farha, O. K., High volumetric uptake of ammonia using Cu-MOF-74/Cu-CPO-27. Dalton Trans. 2016, 45, 
$4150-4153$.

(34) Grant Glover, T.; Peterson, G. W.; Schindler, B. J.; Britt, D.; Yaghi, O., MOF-74 building unit has a direct impact on toxic gas adsorption. Chem. Eng. Sci. 2011, 66, 163-170.

(35) Chen, Y.; Shan, B.; Yang, C.; Yang, J.; Li, J.; Mu, B., Environmentally friendly synthesis of flexible MOFs $\mathrm{M}(\mathrm{NA})_{2}(\mathrm{M}=\mathrm{Zn}, \mathrm{Co}, \mathrm{Cu}, \mathrm{Cd})$ with large and regenerable ammonia capacity. $J$. Mater. Chem. A 2018, 6, 9922-9929.

(36) Godfrey, H. G. W.; da Silva, I.; Briggs, L.; Carter, J. H.; Morris, C. G.; Savage, M.; Easun, T. L.; Manuel, P.; Murray, C. A.; Tang, C. C.; Frogley, M. D.; Cinque, G.; Yang, S.; Schroder, M., Ammonia storage by reversible host-guest site exchange in a robust metal-organic framework. Angew. Chem. Int. Ed. 2018, 57, 14778-14781.

(37) Rieth, A. J.; Dinca, M., Controlled gas uptake in metal-organic frameworks with record ammonia sorption. J. Am. Chem. Soc. 2018, 140, 3461-3466.

(38) Rieth, A. J.; Tulchinsky, Y.; Dinca, M., High and reversible ammonia uptake in mesoporous azolate metal-organic frameworks with open $\mathrm{Mn}, \mathrm{Co}$, and Ni sites. J. Am. Chem. Soc. 2016, 138, 9401-9404.

(39) Feng, D.; Wang, K.; Su, J.; Liu, T. F.; Park, J.; Wei, Z.; Bosch, M.; Yakovenko, A.; Zou, X.; Zhou, H. C., A highly stable zeotype mesoporous zirconium metal-organic framework with ultralarge pores. Angew. Chem. Int. Ed. 2015, 54, 149-154.

(40) Yuan, S.; Lu, W.; Chen, Y. P.; Zhang, Q.; Liu, T. F.; Feng, D.; Wang, X.; Qin, J.; Zhou, H. C., Sequential linker installation: precise placement of functional groups in multivariate metal-organic frameworks. J. Am. Chem. Soc. 2015, 137, 3177-3180.

(41) Furukawa, H.; Gandara, F.; Zhang, Y. B.; Jiang, J.; Queen, W. L.; Hudson, M. R.; Yaghi, O. M., 
Water adsorption in porous metal-organic frameworks and related materials. J. Am. Chem. Soc. 2014, $136,4369-4381$.

(42) Wang, H.; Dong, X.; Lin, J.; Teat, S. J.; Jensen, S.; Cure, J.; Alexandrov, E. V.; Xia, Q.; Tan, K.; Wang, Q.; Olson, D. H.; Proserpio, D. M.; Chabal, Y. J.; Thonhauser, T.; Sun, J.; Han, Y.; Li, J., Topologically guided tuning of Zr-MOF pore structures for highly selective separation of C6 alkane isomers. Nat. Commun. 2018, 9, 1745.

(43) Micek-Ilnicka, A.; Gil, B.; Lalik, E., Ammonia sorption by Dawson acid studied by IR spectroscopy and microbalance. J. Mol. Struct. 2005, 740, 25-29.

(44) Yang, Y.; Faheem, M.; Wang, L.; Meng, Q.; Sha, H.; Yang, N.; Yuan, Y.; Zhu, G., Surface pore engineering of covalent organic frameworks for ammonia capture through synergistic multivariate and open metal site approaches. ACS Cent. Sci. 2018, 4, 748-754.

(45) Petit, C.; Seredych, M.; Bandosz, T. J., Revisiting the chemistry of graphite oxides and its effect on ammonia adsorption. J. Mater. Chem. 2009, 19, 9176-9185. 
Table of Contents (TOC) Graphic

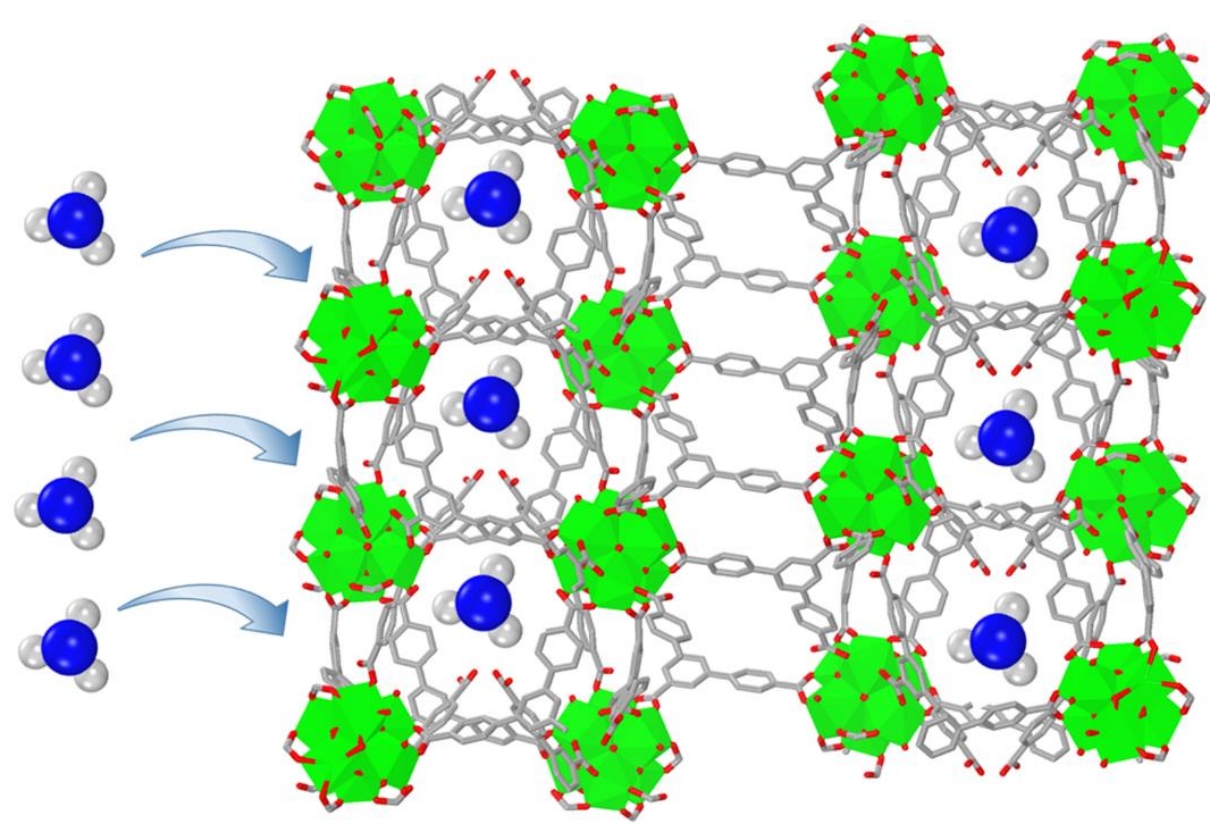

